2 Nathan E. Transient hyperphosphatasaemia of infancy. Acta Paediatr Scand 1980;69:235-8.

${ }^{3}$ Rosalki SB, Foo AY. Transient hyperphosphatasarmia of infancy. Four new cases and a suggested aetiology. Clin Chem 1980:26:1109-10.

\author{
P J Shaw and M J Brueton \\ Westminster Children's Hospital, \\ London SWIP 2NS
}

\section{Waardenburg's syndrome associated with total intestinal aganglionosis}

Sir,

Farndon and Bianchi ${ }^{1}$ reported a Pakistani child with signs of Waardenburg's syndrome associated with total aganglionosis and suggested that this can be a distinct clinical entity with an autosomal recessive mode of inheritance. We reported our experience of 12 such cases and felt that this was a new syndrome with autosomal recessive inheritance. ${ }^{2}$ Later, we came across another patient who was related to family 5 in our previous report ${ }^{2}$ and this extended pedigree was published. ${ }^{3}$ On the basis of our study of this extended pedigree, we have no doubt that inheritance in this syndrome is autosomal recessive while Waardenburg's is an autosomal dominant condition. Farndon's case report lends further support to our impression that this is a distinct clinical entity. It is interesting to note that there are no similar case reports from other parts of the world and we wonder whether any racial factors are involved since the syndrome has been reported only in children of Indian and Pakistani origin to date.

\section{References}

' Farndon PA. Bianchi A. Waardenburg's syndrome associated with total intestinal aganglionosis. Arch Dis Child 1983;58: 932-3.

2 Shah KN, Dalal SJ, Desai MP, Sheth PM, Joshi NC, Ambani LM. White forelock, pigmentary disorder of irides and long segment Hirschsprung's discase, possible variant of Waardenburg's syndrome. J Pediatr 1981;99:432-5.

3 Ambani LM. Waardenburg's and Hirschsprung's syndromes. J Pediatr 1983:102:802.

K N SHaH Bia Jerbai Wadia Hospital for Children, Bombay 400012 , India 